\title{
LA LEGISLACION ESPAÑOLA DE MONTES, Y ESPECIALMENTE DE MONTES CATALOGADOS, EN SUS RELACIONES CON EL REGIMEN PROVINCIAL
}

352: 336.111

por

\section{Eduardo Tarrats y Fontanelles}

Abogado y funcionario de carrera de la Diputación

Provincial de Barcelona

SUMARIO: I. INTRODUCCION.-II. EN GENERAL: 1. LA DESAMORTIZACIÓN Y SUS FRENOS: El Catálogo. 2. IdEAS SOBRe El RÉGIMEN DE LOS MONTES CATALOGADOS Y DE LOS MONTES EN GENERAL.III. EFECTOS DE LA INCLUSION DE LOS MONTES, Y EN ESPECIAL DE LOS PROVINCIALES, EN EL CATALOGO DE LOS DE UTILIDAD PUBLICA: 1. INTRODUCCIÓN. 2. EFECTOS GENERALES. 3. Efectos varios de DeRECho pRIVAdo. 4. EFectos de Derecho INMOBILIARIO. 5. EFECTOS DE TIPO PROCESAL. 6. EFECTOS RELATIVOS A LA ORDENACIÓN Y PLANIFICACIÓN DASOCRÁTICA. 7. EFECTOS RELATIVOS A LA EXPLOTACION Y APROVECHAMIENTO. 8. EFECTOS EN CUANTO A LA POBLACIÓN Y REPOBLACIÓN FORESTAL. 9. EFECTOS EN CUANTO a La lUCHA PLAGUICIDA. 10. EFECTOS EN CUANTO a POLICÁa Y RÉGIMEN SANCIONADOR. 11. EFECTOS EN CUANTO AL DERECHO FISCal.-IV. EPILOGO: Sobre Si conviene a las Diputaciones ProviNCiales PEdir la inClustón de sus montes EN El Catálogo.V. ANEXO. 


\section{INTRODUCCION}

Si tenemos en cuenta que una buena parte de los montes españoles están en manos de la Administración e incluidos en un Catálogo de montes de utilidad pública y un especialista en Derecho forestal (AURElio Guaita) declara que la mayor parte de los montes catalogados son provinciales, la consecuencia lógica sería que una parte de los letrados provinciales esté especializada en Derecho forestal y que el resto tenga nociones claras sobre la materia.

Sin embargo, como algunas Diputaciones hasta fecha reciente no se han lanzado a una política de adquisición de suelo forestal, hay pocos letrados con algún conocimiento sobre la materia, conocimiento que es necesario, por lo expuesto, que adquieran rápidamente todos los funcionarios relacionados con ella.

Este escrito tiende a facilitar este aprendizaje desde la perspectiva de los intereses y las preocupaciones provinciales.

Antes de seguir adelante es lógico que el lector se pregunte por el concepto de monte.

En nuestra legislación se parte de la acepción 2 del Diccionario de la Real Academia: tierra inculta, cubierta de árboles, arbustos o matas. Pero se delimita del siguiente modo:

«Se entiende por monte o terreno forestal la tierra en que vegetan especies arbóreas, arbustivas, de matorral o herbáceas, sea espontáneamente o procedan de siembra o plantación, siempre que no sean características del cultivo agrícola o fueren objeto del mismo" (arts. 1, 2, de la Ley de Montes de 8 de junio de 1957 y 4, 1, de su Reglamento).

Luego, se producen unas extensiones y unas exclusiones por motivos prácticos:

«Bajo dicha denominación se comprenden también los terrenos que, aun sin reunir las condiciones determinadas en el párrafo anterior, hayan quedado o queden adscritos a la finalidad de ser repoblados o transformados en terrenos forestales como consecuencia de resoluciones administrativas dictadas conforme a las leyes que regulan esta materia.

Como excepción a lo establecido en el párrafo primero, no se reputarán montes, a efectos de la legislación forestal, los terrenos que, formando parte de una finca fundamentalmente agrícola y sin estar cubiertos apreciablemente con especies arbóreas o arbustivas 
de carácter forestal, resultaren convenientes para atender al sostenimiento del ganado de la propia explotación agrícola, así como los prados desprovistos sensiblemente de arbolado de dicha naturaleza y las praderas situadas en las Provincias del litoral cantábricon (artículos 1, 2, de la Ley de Montes y 4, 2 y 3, de su Reglamento).

Por tanto, queda claro que «monte», en sentido legal, no equivale a «bosque». Hasta tal punto es efectiva la distinción que no se contabilizan (1) en las estadísticas de incendios encinares, e incluso robledos, como bosques. El motivo es que en algunas Regiones (Extremadura, por ejemplo) el fuego es un medio de cultivo o regeneración de los pastos, poblados de encinas y robles. (Claro está, tanto la inclusión como la exclusión sistemática falsean las estadísticas.)

\section{EN GENERAL}

\section{La desamortización y sus frenos: El Catálogo}

Es sabido que, en España, la corriente desamortizadora se llevó por delante la propiedad inmueble del Estado, de los Municipios y Entes locales inferiores, de la Iglesia y de los Entes eclesiásticos. No hablo de las Provincias porque, creada la nueva división provincial por Decreto de 30 de noviembre de 1833 y siendo las leyes desamortizadoras de mayor impacto las de 29 de julio de 1837 y de 24 de septiembre de 1841, parece difícil que pudieran existir propiedades en las que cebarse la desamortización.

De hecho, la primera Ley desamortizadora que menciona las Provincias es la de 11 de julio de 1856, la cual modificó la de 1 de mayo de 1885, que es el núcleo más importante de esta legislación, que puede ya considerarse totalmente derogada, quedando-quizá-en vigor para las Entidades estatales autónomas (2).

Según el artículo 2, número 4, de la Ley de 1 de mayo de 1885, se salvaban de la desamortización los «montes y bosques cuya venta no crea oportuna el Gobierno». El Gobierno manifestó su criterio a través de un Decreto de 26 de octubre de 1885, que clasificaba los montes en tres clases:

(1) Según informa R. BALADA I Llasat en su Estudi dels incendis forestals a les comarques de Barcelona, noviembre de 1976, redactado bajo el patrimonio de la Diputación Provincial de Barcelona.

(2) Para la Iglesia y sus personas morales se entiende derogada por la Ley de 4 de abril de 1860; para las Provincias, por el Estatuto de 20 de mayo de 1925; para los Municipios, por la Ley de 10 de julio de 1935, y para el Estado, por el texto articulado de 15 de abril de 1964 de la Ley del Patrimonio del Estado. 
1. $\quad$ Montes que deban conservarse sujetos a las Ordenanzas del ramo y que se exceptúan, por tanto, de la enajenación.

2. ${ }^{a} \quad$ Montes de enajenación dudosa.

3. ${ }^{a} \quad$ Montes que se declaran desde luego en estado de venta.

La segunda clase era provisional; después del oportuno expediente, en el que habían de formarse sendos inventarios provinciales de los montes de dicha clase, habían de pasar a la primera o a la tercera.

Según el artículo $2 .^{\circ}$ del Decreto, eran de la primera clase los montes de abetos, pinabetos, pinsapos, pinos, enebros, sabinas, tejos, hayas, castaños, avellanos, abedules, alisos, acebos, robles, rebollos, quejigos y piornos, cualesquiera que sean sus especies, su método de beneficio y la localidad donde se hallaren.

Para introducir claridad y control en el tema, el Real Decreto de 22 de enero de 1862 ordenó formar un catálogo de montes exceptuados de venta.

La Ley de 24 de mayo de 1863, sobre montes, fue menos generosa. Según su artículo $2 .^{\circ}$, quedaban exceptuados de la venta prescrita por la Ley de desamortización solamente los montes públicos de pinos, robles o hayas, cualesquiera que sean sus especies, siempre que consten por lo menos de 100 hectáreas.

Quizá por razón de las dificultades de medir las 100 hectáreas, el artículo $4 .^{\circ}$ adicional de dicha Ley establecía de nuevo que «el Ministerio de Fomento publicará un catálogo de los montes exceptuados de la venta, con arreglo a los artículos de la presente Ley».

El Reglamento de 17 de mayo de 1865 insistió en la exceptuación de venta, "aclarando» que se exceptuaban los bosques de pinos, robles o hayas, siempre que por sí solos, o unidos a otros que disten menos de un kilómetro entre sí, consten al menos de 100 hectáreas.

Hemos visto aparecer el catálogo antes que la denominación «de utilidad pública».

La expresión aparece por primera vez en la Ley de 30 de agosto de 1896, sobre modificación de impuestos, y luego en el Decreto de 20 de septiembre de 1896, que ordena la formación de un nuevo catálogo en el que el criterio de inclusión no son los géneros o especies arbóreas, sino la función ecológica del bosque: "garantir (!), por su influencia física en el país o en las comarcas naturales donde tenga su asiento, la salubridad pública, el mejor régimen de las aguas, la seguridad de los terrenos o la fertilidad de las tierras destinadas a la agricultura». A partir de esta fecha la denominación de montes de utilidad pública, aunque inicialmente coexiste con la más 
descriptiva de montes públicos exceptuados de la desamortización, por razones (o por causa) de utilidad pública, se va imponiendo, quizá como consecuencia del debilitamiento de la presión desamortizadora.

Ultimamente, por razones de evidente comodidad, se tiende a usar la de «montes catalogados». Pero la actual Ley de Montes emplea ésta y la de «montes de utilidad pública», abundante e insistentemente, como sinónimas.

También últimamente (en la Ley 15/1975, de espacios naturales protegidos) se habla, de un modo breve pero incorrecto, de «Catálogo de Utilidad Pública»-art. 13, a), de la citada Ley-. Pero la denominación completa es la de "Catálogo de Montes de Utilidad Pública», aunque la propia Ley de Montes al definir el Catálogo la reduzca:

«El Catálogo de Montes es un Registro público de carácter administrativo en el que se incluirán todos los montes que hubieren sido declarados de utilidad pública pertenecientes al Estado, a las Entidades públicas territoriales y a los Establecimientos públicos de Beneficencia o Enseñanza.»

Los criterios para la inclusión siguen siendo los del añejo Decreto de 20 de septiembre de 1890, completados (y precedidos) por otros. Dice así el vigente artículo 25 del Reglamento de Montes, aprobado por Decreto 485/1962, de 22 de febrero:

«Se propondrá la declaración de utilidad pública de todos los montes públicos o terrenos forestales de carácter público que se hallen en alguno de los casos que se citan a continuación:

A) Los existentes en las cabeceras de las cuencas hidrográficas.

B) Los que en su estado actual, o repoblados, sirvan para regular eficazmente las grandes alteraciones del régimen de las aguas llovidas.

C) Los que eviten desprendimientos de tierras o rocas, formación de dunas, sujeten o afirmen los suelos, defiendan poblados, cultivos, canalizaciones o vías de comunicación, impidan la erosión de suelos, en pendiente, y el enturbiamiento de las aguas que abastecen poblaciones.

D) Los que saneen parajes pantanosos.

E) Los montes que con su aprovechamiento regular sirvan para hacer permanentes las condiciones higiénicas, económicas y sociales de pueblos comarcanos.

F) Y, en general, cuando se trate de masas de arbolado o terrenos forestales que, dadas su condiciones de situación o de área, sea preciso conservar o repoblar por su influencia económica o física en la Nación o Comarca, la salubridad pública, el mejor régimen de las aguas, la se- 
guridad de los terrenos, la fertilidad de las tierras destinadas a la agricultura o por su utilidad para la defensa nacional, previo requerimiento de la autoridad militar.»

Desde la Ley 15/1975, de 2 de mayo, de espacios naturales protegidos, existe un nuevo caso de inclusión:

«Los montes y terrenos forestales, entendiendo por tales los que se definen en el artículo 1. de la Ley de Montes de 8 de junio de 1977, pertenecientes a Entidades públicas, quedarán, si no lo estuvieren, incluidos en el Catálogo de los de Utilidad Pública... Las correspondientes inclusiones se realizarán, previo el oportuno expediente... [art. 17, a), del Reglamento de la Ley de espacios naturales protegidos].

El texto de la Ley (que en su artículo 13 dice que la declaración de parque natural por el Gobierno lleva consigo la inclusión en el Catálogo de los montes públicos que formen parte de aquél) podía hacer pensar en un caso de declaración «indirecta» u ope legis de monte de utilidad pública, pero el Reglamento, en el lugar citado, exige la instrucción formal de expediente, echando por tierra esa posible interpretación. Esta inclusión, por cierto, será un tanto desconcertante, porque la gestión de los montes públicos está orientada a obtener el mayor rendimiento posible mediante la correcta aplicación de las técnicas dasocráticas, pero en los parques naturales de lo que se trata es de conservar las masas vegetales y, en general, los ecosistemas en su estado primitivo, obteniendo, digámoslo así, el menor rendimiento posible.

El contenido y funcionamiento del Catálogo están regulados con cierta extensión en el título II del libro II del actual Reglamento de Montes, así como también los efectos en Derecho civil, procesal civil e inmobiliario registral. Los aspectos de funcionamiento formal y de adaptación del Registro de la Propiedad al Catálogo, a fin de evitar discrepancias entre ambas instituciones, fueron regulados por la Orden ministerial de 31 de mayo de 1966, todavía vigente.

Merece destacarse que el artículo 16 de la vigente Ley de Montes y los artículos 149 y 150 del Reglamento (en título distinto del antes citado), ponen especial énfasis en el reflejo en el Cátalogo de las servidumbres y demás derechos reales que gravan los montes inscritos. 


\section{IDEAS SOBRE EL RÉGIMEN DE LOS MONTES CATALOGADOS $Y$ DE LOS MONTES EN GENERAL}

Es característico en el régimen de los montes catalogados una acusada intervención del Estado, aunque actualmente se efectúe a través de un órgano con personalidad propia: el Instituto para la Conservación de la Naturaleza (ICONA), creado por Decreto-Ley 17/ 1971, en el que se refundieron el Patrimonio Forestal del Estado, el Servicio de Pesca Continental, Caza y Parques Naturales, la Dirección General de Montes y sus Jefaturas regionales y provinciales, y que asumió algunas funciones del Servicio de Plagas Forestales que, en cuanto al grueso de sus funciones, quedó fusionado con otro.

Esa acusada intervención no es exclusiva, en la actualidad, de estos montes. Se extiende a todos y últimamente lo ha intensificado (aunque poniendo el acento en los aspectos de fomento: subvenciones, auxilios, desgravaciones) la Ley 5/1977, de Fomento de la Producción Forestal. La intervención es muy fuerte en los llamados montes protectores. Si los montes catalogados son los de utilidad pública y propiedad también pública, los montes protectores, grosso modo, podrían definirse como montes de utilidad pública y propiedad particular, a los que se aplica parte de la legislación sobre montes catalogados y para los que, en parte, se estatuye un régimen imitado del de éstos. Así, por el Consejo de Ministros se aprueban unas relaciones de montes protectores que son un remedo de las de inclusión en el Catálogo. En cambio, la intervención estatal es mucho más débil en los montes públicos no catalogados y decrece aún algo en los montes de particulares que no tengan el carácter de protectores.

Quede, pues, claro que en los montes, tanto de propiedad privada como de propiedad pública, la influencia estatal no es uniforme, sino que tiene ciertas gradaciones. La intervención y protección es más intensa en los conjuntos administrativos de montes de los que hay gran diversidad de figuras (malum signum!) en nuestra legislación: agrupaciones forestales voluntarias o forzosas (artículos 247 y siguientes del Reglamento de Montes) (3), zonas de repoblación obligatoria (art. 316 del mismo), Comarcas declaradas

(3) Una figura que guarda cierto paralelismo con los parques naturales. 
de interés forestal (según Ley de 10 de mayo de 1971) (4), «zonas de peligro" de incendio con planes generales de defensa previamente aprobados (cuya normativa se cita más adelante), zonas protectoras, zonas declaradas protectoras de carácter hidrológico-forestal, parques nacionales y parques naturales, cuya finalidad no es utilitaria o económica como los anteriores conjuntos. Si contemplamos montes aislados, el primer lugar corresponde a los «catalogados de utilidad pública» y, dentro de éstos, a los del Estado adscritos a ICONA, siguiendo luego los de los entes locales, pero, en muchos aspectos prácticos, el primer puesto les sería seguramente disputado por los "consorciados» (5); siguen luego los montes en mejora o en repoblación con ayuda estatal y, en un grado más bajo, los protectores, si no estuviesen incluidos en alguno de los grupos anteriores. Y la intervención y protección es mucho más débil en los montes que no tienen ninguna de estas afectaciones, pero incluso dentro de éstos hay gradaciones: podríamos decir que el último lugar de la escala lo ocupan los montes espartizales de particulares (6).

Ahora bien, esta intervención respecto a los montes de propiedad pública no es nueva, sino que procede de la Real Orden de 22 de diciembre de 1833 (7), aprobatoria de las Ordenanzas Generales de Montes. En éstas, las mismas por las que se creó la Dirección General de Montes (que ha durado hasta 1971), existía un artículo clara y prematuramente intervencionista: "Quedan también dependientes de la guarnición (sic) y conservación de la Dirección General, y con sujeción al régimen prescrito en estas Ordenanzas: $10^{\circ}$ Los montes propios o comunes de los pueblos. $2 .^{\circ}$ Los pertenecientes a hospi-

(4) Obsérvese la superposición de dos figuras jurídicas análogas: la declaración de interés forestal y la declaración de repoblación obligatoria (art. 50 de la Ley de Montes), que dan lugar a ayudas, expropiaciones y consorcios. Probablemente es debido a haber omitido, involuntariamente, la supresión de la «declaración de interés forestal», quizá porque su poca utilización produjo el olvido de esa figura.

(5) Los «consorciados» son los montes en que el ICONA tiene un derecho real de suelo y, por tanto, una participación en los beneficios de la explotación, ya sea en virtud de un contrato de constitución del consorcio, ya sea impuesto por dicho organismo o su antecesor, el Patrimonio Forestal del Estado. Vide el libro III del Reglamento de Montes y los artículos 73, 81 y 82 del Reglamento del Patrimonio Forestal, aprobado por Decreto de 30 de mayo de 1941 . La reciente Ley 5/1977 y su Reglamento de Fomento de Producción Forestal, por razones técnico-jurídicas y de tipo psicológico, sustituyen el «consorcio» por el "convenio», pero la figura jurídica que regulan es la misma.

(6) Nos duele tener que advertir que respecto a los montes de propiedad privada existen posibilidades legales de protección y mejora, no aprovechadas, y que en la práctica la intervención no es demasiado efectiva: en algún caso se han talado diez veces más árboles que los autorizados, sin que la reacción de la Administración fuese medianamente enérgica.

(7) Debida a Javier DE BURGos, que aquí nos muestra un centralismo descarnado que supera el de los centralistas de nuestra época. 
LA LEGISLACION DE MONTES EN SUS RELACIONES CON EL REGIMEN PROVINCIAL

cios, hospitales, universidades $\mathrm{u}$ otros establecimientos públicos dependientes de mi Real protección y gobierno; y 3. Aquellos en que la Real Hacienda, los pueblos o los establecimientos públicos tengan condominio o comunidad de disfrutes o usos con otro cualquiera propietario» (art. 5..$^{\circ}$.

Si la Orden no habla de las Provincias ni de las Diputaciones es porque se acaban de crear, y quizá porque las Diputaciones se consideraban como «establecimientos»; pero es un texto absolutamente tajante, de modo que los montes provinciales, de haberlos, quedaban bajo la autoridad de la Dirección General de Montes.

Lo que, por tanto, se produjo en la evolución legislativa es una separación entre el régimen de los montes catalogados y el de montes no catalogados, separación que ya tenía un precedente en el artículo 19 de las Ordenanzas de 1883, según el cual «todo monte de propios, del común o de establecimientos públicos que ni tenga arbolados ni parezca apto para criarlos» se «entregaba» por la Dirección General de Montes a sus titulares. Pero el momento álgido de esta separación pertenece al pasado, porque suponía una rigurosa no intervención en los montes de dominio privado, supuesto del que estamos oficialmente (como se acaba de demostrar) bien lejos. Sin embargo, la importancia que sigue teniendo justifica el enfoque dado a este estudio.

Como acabamos de exponer, incluso dentro de cada tipo de monte público el régimen no es uniforme. La legislación forestal distingue, por una parte, entre bienes del Estado, de las Entidades locales y de las demás Corporaciones, y por otra, entre bienes patrimoniales y bienes de dominio público (adscritos al uso o al servicio público).

En los del Estado (inscritos a nombre de éste) ICONA desempeña, lógicamente, el papel de administrador privado y de Administración pública.

Los de las Entidades locales se distinguen según sean bienes provinciales o de Cabildos insulares o bienes municipales. Una variedad importante de los municipales patrimoniales son los comunales (aprovechados consuetudinariamente por los vecinos de una localidad).

Un caso especial, que cabalga entre la propiedad privada y la pública, es el de los montes pertenecientes a los vecinos integrantes en cada momento del grupo comunitario rural (parroquia, aldea, lugar, etc.) de que se trate, regulado por la Ley 52/1968, de 27 de 
julio, y su Reglamento de 26 de febrero de 1970. Para estos montes se ha previsto su exclusión del Catálogo de los de Utilidad Pública y su inclusión en unas relaciones especiales de montes vecinales en mano común.

La actual normativa básica en esta materia está integrada por la Ley de Montes de 8 de junio de 1957 y el Reglamento de Montes aprobado por Decreto 485/1962, de 22 de febrero. Pero regulando aspectos más específicos hay que destacar la Ley de 10 de marzo de 1941, sobre Patrimonio Forestal del Estado; su Reglamento de 30 de mayo de 1941; el Decreto 2479/1966, de 10 de septiembre, sobre mejoras en los montes de las Entidades locales; la citada normativa sobre montes vecinales en mano común; la Ley 81/1968, de 5 de diciembre, sobre incendios forestales, y su Reglamento aprobado por Decreto 3769/1972, de 23 de diciembre; el Decreto-Ley 17/1971, citado al principio de este capítulo, por el que se modifica la Administración institucional del Ministerio de Agricultura; la Ley 15/ 1975, de 2 de mayo, de espacios naturales protegidos, y su Reglamento aprobado por Decreto 2676/1977, de 4 de marzo, y la ya citada Ley $5 / 1977$, de fomento de la producción forestal, con su Reglamento aprobado por Decreto 1279/1978, de 2 de mayo.

Existen otras disposiciones especiales que se pueden considerar de tercer rango, algunas de las cuales serán citadas a lo largo de este trabajo.

El conjunto de la normativa vigente está recogido en el excelente tomo modestamente titulado Ley y Reglamento de Montes, publicado y varias veces puesto al día por el Boletín Oficial del Estado en su colección "Textos Legales» (pero cuya fecha de última reedición ignoro), sin cuya ayuda el presente trabajo no hubiera, probablemente, podido realizarse.

\section{EFECTOS DE LA INCLUSION DE LOS MONTES, Y EN ESPECIAL DE LOS PROVINCIALES, EN EL CATALOGO DE LOS DE UTILIDAD PUBLICA}

\section{INTRODUCCIÓN}

Los efectos de la inclusión de un monte en el Catálogo son muy extensos. Ahora bien, la acentuada tendencia intervencionista apuntada en el capítulo anterior tiende a asimilar el régimen de los otros tipos de montes al de éstos. De ahí que, a veces, los efectos sean mayores en el papel que en la realidad. En todo caso, hemos procu- 
rado destacar las diferencias, de modo que no citamos, en general, las normas que no distinguen realmente entre montes catalogados y no catalogados.

Hemos procurado presentar agrupados los efectos relativos a los mismos aspectos y al final de cada texto indicamos la fuente in. formativa.

Esto nos ha obligado a utilizar una serie de abreviaturas según el siguiente cuadro:

D. $=$ Decreto.

L. = Ley de Montes (salvo cuando sigue una determinación, en cuyo caso significa la ley indicada por la misma).

LRL = Ley de Régimen local, texto articulado de 24 de junio de 1955.

O. = Orden.

R. $\quad=$ Reglamento de Montes.

RBEL = Reglamento de Bienes de las Entidades locales de 27 de mayo de 1955.

R. Inc. For. = Reglamento de Incendios Forestales.

ss. $\quad=$ siguientes.

Advirtamos que todos los puntos regulados en la L. se tratan también en el R., de modo que se citan sólo en el R. cuando su texto constituye una ampliación de lo tratado en la L. o depende de otra fuente legal. El número que en la cita precede a la abreviatura es el del artículo o precepto.

\section{EFECTOS GENERALES}

Consideración erga omnes como montes de utilidad pública mientras no se acuerde legalmente su exclusión. Este efecto es tan general y esencial que puede decirse que todos los demás son consecuencia de éste y el objetivo perseguido por el Catálogo (41 R.).

Consideración [limitada a los provinciales (8)] como bienes de servicio público $\mathrm{y}$, por tanto, de dominio público (282 LRL y 4-2 RBEL).

No afectación por un plan parcial de ordenación (ni por ningún

(8) Es curiosa esa limitación a los provinciales. Quizá está motivada porque, sobre todo en 1955, la mayor parte de los montes municipales eran de propios o comunales. Hay que notar que el artículo $11 \mathrm{R}$. podría servir de base para restringir la 
otro plan derivado de la Ley del Suelo) sin previo informe del Ministerio de Agricultura (9) (28 L. y 30 R.).

Exclusión de la concentración parcelaria cuando estén incluidos dentro de una zona declarada legalmente en concentración (13-2 L.). No obstante, sí puede producirse un efecto secundario de la concentración (aparte de la delimitación de que se habla posteriormente): un nuevo trazado de las vías pecuarias en consonancia con las necesidades de la concentración y con las de la ganadería (186-1 L. y D. 118/1973).

\section{Efectos varios de DeRecho privado}

En relación con el tráfico jurídico:

- Enajenabilidad sólo mediante ley, en principio. Está prevista la cesión al ICONA, de acuerdo con lo dispuesto en la Ley de Montes y demás disposiciones legales que afecten a la Entidad propietaria, cuando las obras preventivas de incendios en Comarcas declaradas «zonas de peligro» tengan un importe excesivo con relación al valor del monte o su aprovechamiento (44-1 R. y 8-1 y 50 R. Inc. For.).

- Expropiabilidad, no obstante, por obras y trabajos cuyo interés general prevalezca sobre la utilidad pública del monte afectado. Salvo conformidad expresa del Ministerio de Agricultura (10), tal preferencia debe declararse por ley o por acuerdo del Consejo de Ministros, previo expediente con audiencia del Ministerio de Agricultura. (45 y 46 R.).

- Hipotecabilidad de los aprovechamientos, no obstante la no

calidad de dominio público de los montes catalogados provinciales a los que, realmente, estén adscritos a un servicio público, pero se hace difícil admitir una interpretación restrictiva de una ley por un reglamento de otra rama jurídica (y que, además, nos parece de redacción infortunada). Respecto al Estado, no hay una declaración automática. Pero como, según la Ley del Patrimonio del Estado, número 1022/1964, la inclusión en el Inventario General de Bienes y Derechos del Estado de los bienes que integran el patrimonio forestal del mismo no impide (disposición de excepción 4.") que se rijan por su legislación peculiar, una interpretación sistemática de esta legislación nos llevaría a considerar la catalogación como sinónima de declaración de servicio público y a extenderla a los municipales.

(9) Debe advertirse que el Reglamento generaliza la necesidad del previo informe que la Ley prevé sólo para los planes parciales.

(10) Esa conformidad no será difícil de otorgar cuando la expropiación sea promovida por un organismo del propio Ministerio. Tales son los casos en que se necesita disponer de terrenos para el emplazamiento de las obras especiales que exija la técnica hidrológico-forestal, como diques, canalizaciones o cualesquiera otras, supuestos en los que ya el artículo $347 \mathrm{R}$. prevé la expropiación, «aun cuando se trate de terrenos incluidos en montes catalogados». 
enajenabilidad del monte, mediante los trámites reglamentarios, que incluyen la previa conformidad del Ministerio de Agricultura (44-3 y 151 ss. R.).

- Inembargabilidad; pero, no obstante, como puede hipotecarse el aprovechamiento, podrá también embargarse el aprovechamiento en ejecución de esa específica garantía. Por lo demás, es principio general que los bienes de los entes locales son inembargables (44-2 R.).

- Son usucapibles en un plazo ininterumpido de treinta años, previos otros veinticinco en los que el destino del monte debe haber estado en contradicción con su concepto de monte de utilidad pública. La necesidad de computar dos plazos para los montes provinciales procede de su afectación como bienes de servicio público por el mero hecho de su catalogación y de que el artículo 8-5 del RBEL entiende producida la desafectación de los bienes de dominio público cuando hubiesen dejado de utilizarse en el sentido de la afectación pública durante veinticinco años. Como en este caso la afectación al servicio público es consecuencia no de un uso, sino de una declaración formal por la Administración Central, la de utilidad pública (art. 28 R.) fundada en unas determinadas características, debe exigirse por la desafectación no una utilización "heterodoxa" cualquiera, sino una que sea -como hemos dicho de otro modo arriba-incompatible con aquellas características. De otro modo se facilitaría enormemente el burlar los efectos de la catalogación (64-1 R.).

- Imprescriptibilidad (por no ejercicio de las facultades dominicales), salvo desafectación en el tiempo y forma explicados en el párrafo anterior (64-3 R.).

- Refundición de los derechos de suelo y vuelo (si se hubieren separado) a favor del dueño del vuelo (dominio que ha hecho posible la catalogación del monte), con informe preceptivo del Departamento de Agricultura, e indemnización fijada según la Ley de Expropiación forzosa (11) (23 L. y 13 R.).

- Posibilidad de permuta total o parcial con otros montes catalogados o no, cualquiera que fuese su dueño (incluso el

(11) El Reglamento ha restringido a los montes catalogados un beneficio que en la Ley podría ser para todos los montes cuyo suelo fuera de propiedad pública. En cambio, ha introducido una norma sobre redención de censos que parece ser aplicable a todos los montes "públicos», catalogados o no, pero a la que no creemos que los tribunales puedan reconocer prioridad sobre las normas de Derecho civil (18 R.). 
Estado), cumpliendo las determinaciones de la legislación de Régimen local (185 R. y 26 y 27 L.).

Si todos son catalogados, basta dar cuenta al ICONA del acuerdo alcanzado y al Ministerio del Interior. En otro caso se precisa autorización del Ministerio de Agricultura, previa instrucción de expediente por ICONA (185 R. y 95-3 y 4 RBEL).

En todo caso, se precisa de:

- Tasación por Ingeniero de Montes, no necesariamente por ICONA (186 R.).

- Escritura pública inscrita y remisión de copia autorizada al ICONA (187 R.).

Cuando la condición de bien de dominio público le prevenga exclusivamente al monte de su catalogación, entiendo que para la permuta no se precisa previa desafectación (la misma se produce por su exclusión del Catálogo). Pero sí en los demás casos.

- Indivisibilidad, cuando pertenezcan en comunidad a varios dueños, sin autorización del Ministerio de Agricultura (para asegurar que ninguna de las unidades resultantes es inferior a la unidad mínima de monte fijada por el mismo Ministerio) (188 R.).

En relación con el régimen jurídico de las servidumbres y otros derechos reales:

- Determinación por la Administración de la condición juridica de las servidumbres y de los demás derechos reales existentes (16-2 R.).

- Posibilidad de determinación por el Ministerio de Agricultura, a propuesta del ICONA, de la existencia o legitimidad de alguna servidumbre $u$ otro derecho real (si no resultase debidamente justificada de los antecedentes de que disponga la Administración). Sin embargo, la resolución no modifica per se la inscripción en el Registro de la Propiedad (si existiese): es preciso que la convierta el titular o que haya recaído resolución judicial firme (155 ss. y $158 \mathrm{R}$.).

- Posibilidad de extinción o suspensión temporal por el Ministerio de Agricultura de cualquier servidumbre establecida sobre un monte catalogado, aunque esté inscrita, cuando se estime que es incompatible con las condiciones esenciales 
del monte gravado o con el fin de utilidad pública a que estuviere afecto (12). Para que la extinción o suspensión se indemnice, valorada según la Ley de Expropiación forzosa, salvo acuerdo entre las partes, es preciso que la servidumbre afectada se funde en título legítimo. En otro caso, es decir, en caso de derecho de servidumbre in fieri, en formación, puede conceder el Gobierno indemnización teniendo presente circunstancias de equidad (13) (159 ss. y 167 R.).

- Posibilidad (inversa de la anterior) de que el ICONA establezca servidumbres o autorice ocupaciones de carácter temporal, siempre que se justifique la compatibilidad de unas y otras con el fin y la utilidad pública a que estuviere afecto el monte, con canon o justiprecio determinado siguiendo las reglas de la Ley de Expropiación forzosa (20 L. y 172 R.).

Si se trata de servidumbre $u$ ocupación de interés público, en caso de discrepancia del ICONA con el Departamento de que dependa la obra o servicio, el expediente se eleva al Ministerio de Agricultura (175, 176, 179 y 180 R.).

Si el Ministerio de Agricultura o la Entidad propietaria se oponen, la resolución deberá ser tomada por el Consejo de Ministros. Sin embargo, no obsta la inclusión en el Catálogo:

a) Para la imposición de servidumbres de paso de energía eléctrica, conforme a su legislación especial (D. 2619/1966, art. 14-3).

b) Para el emplazamiento de obras especiales, como diques, canalizaciones o cualesquiera otras que exijan la técnica hidrológico-forestal y la consiguiente expropiación por el ICONA con este fin (374 R.).

En relación con la posesión y el ejercicio de los derechos:

- Presunción de posesión por la Entidad a cuyo nombre figuren catalogados (10 L.).

- Mantenimiento en la posesión y asistencia en la recuperación por el Gobierno Civil de la Provincia, salvo reconocimiento

(12) Hay un supuesto, servidumbre a favor de una comunidad de vecinos, en que es preceptiva la intervención del Consejo de Ministros.

(13) La indemnización por pérdida de la expectativa de un derecho y por el mismo perjudicado por la expectativa es una norma «extravagante», pero que puede allanar muchas dificultades. 
de la posesión por la Administración forestal (ICONA) (10 L. y 67 R.).

- Ejercicio del derecho de propiedad conforme a las normas de la LRL (pero véanse los apartados siguientes de este capítulo, en especial el 6) (4-1 R.).

En relación con la determinación del objeto del derecho:

- Competencia de la Administración forestal (ICONA), incluso de oficio, para el apeo, el deslinde y el amojonamiento, para su publicidad y para la resolución de las reclamaciones contra estas operaciones. Todo ello conforme a complejas normas legales $\mathrm{y}$ a pródigas normas reglamentarias $\mathrm{y}$ con posibles medidas precautorias de la propia Administración (12 a 15 L.).

- Deber de proceder a una delimitación urgente en caso de concentración parcelaria, para el único efecto (unicidad que no nos parece fácil) de excluir el monte de la concentración, según lo expuesto anteriormente (136 ss. R.).

\section{EFEctos DE DeRECho INMOBILIARIo}

- Inscripción (obligatoria) en el Registro de la Propiedad. Se efectúa mediante certificación de la administración del Catálogo, tanto si el monte está deslindado como si no lo está, en cuyo caso, cuando se haya efectuado el deslinde, se hará constar por nota marginal (11-1 L. y 80 R.).

- Obtención (obligada) de anotación preventiva de deslinde, haya o no previa inscripción, durante la tramitación del expediente de deslinde. Esta anotación surte los mismos efectos que la anotación preventiva de demanda (11-2 L.).

- Condicionamiento de la inmatriculación de las fincas colindantes a la obtención (estableciéndose silencio administrativo positivo) de certificado de la Administración forestal de que las fincas no están incluidas en los montes catalogados (11-4 L.).

- Reducciones, según el Decreto de 6 de junio de 1958, en los derechos de los registradores en las inscripciones realizadas en virtud de lo dispuesto en la Ley de Montes $(11-7 \mathrm{~L}$. y D. $3234 / 1971)$. 


\section{EFECTOS DE TIPO PROCESAL}

Es necesaria para todo proceso civil no sólo la reclamación previa en vía administrativa contra la Entidad propietaria, sino también contra el Estado. En caso de deslinde se entiende efectuada mediante la reclamación contra la Orden motivada que ponga término a la vía administrativa (55 R.).

La falta de emplazamiento al Abogado del Estado es causa de nulidad de actos y de impedimento para la ejecución judicial o administrativa de la sentencia recaída (54 R.).

En los juicios de pertenencia, titularidad registral o deslindes, o en los procedimientos judiciales para la inscripción registral, además de la Entidad pública de que se trate, es parte el Estado (11-6 L.).

Los juicios civiles se celebran ante juez de capital con Audiencia territorial (después de haber agotado la vía gubernativa) (11-6 L.).

Las personas que hubieren intervenido como partes en el expediente de deslinde y resultaran afectadas por la resolución administrativa podrán impugnarla ante la Jurisdicción Contencioso-Administrativa, sin que en ella puedan plantearse cuestiones relativas al dominio o a la posesión del monte, ni cualesquiera otras de naturaleza civil (que se plantearán en juicio de esta naturaleza) (15-2 L.).

La ejecución de las sentencias relacionadas con la propiedad se efectuará con la intervención de la Administración forestal del Estado (o sea, el ICONA) y audiencia de la Entidad propietaria (63 R.).

Exclusión de la intervención judicial de la Administración, prevista por el artículo 1.1419 de la Ley de Enjuiciamiento Civil, para determinados litigios (61 R.).

La posesión no podrá ser combatida por interdictos, la acción del artículo 41 de la Ley Hipotecaria u otro procedimiento análogo (68 R. y 10 L.).

Se requiere previo informe del Abogado del Estado para acudir al Juzgado de Primera Instancia en demanda de la inmatriculación suspendida por el registrador, de conformidad con el artículo 306 del Reglamento Hipotecario (76 R.). 


\section{EFECTOS RELATIVOS A LA ORDENACIÓN Y PLANIFICACIÓN DASOCRÁTICA}

La necesidad e intensidad de los trabajos de ordenación de montes catalogados es determinada por la Administración forestal (14) (O. 21-12-1971).

Es obligatoria la redacción (con subordinación a lo dispuesto por la Administración forestal, es decir, por el ICONA, que implícitamente queda autorizada a la redacción directa del Plan por incumplimiento de la obligación) y puede serlo la ejecución (dispuesta, en su caso, por Decreto) de planes de mejora. El concepto de mejora tiene una curiosa amplitud: incluye cualquiera "de orden técnico, social, económico o financiero que contribuya a la prosperidad de la finca». La declaración de ejecución obligatoria implica la ejecución, con carácter forzoso, por la Administración forestal, de las obras y trabajos correspondientes (y con cargo a la misma). En otro caso se prevé la concesión de subvenciones para mejoras y, más concretamente, el señalamiento de una cantidad anual en los presupuestos totales de gastos del ICONA (15) (29-3 y 34 L. y 332 y 334 ss. R.).

Quedan sometidos los montes catalogados a proyectos de ordenación económica y, en tanto no se aprueben, se sujeta el aprovechamiento a planes técnicos adecuados, redactados gratuitamente por los servicios del ICONA (16), que abarcarán un período de diez años y que sólo en casos especiales, debidamente justificados y previa autorización de la Dirección General del ICONA, podrán variarse (29-2 L., 204 ss. R. y Normas O. 29-7-1971).

Mientras no se redacten los correspondientes planes técnicos, de acuerdo con lo dispuesto por las Normas Generales aprobadas por

(14) La misma norma rige en los protectores.

(15) Sin embargo, las mejoras se prevén (y se subvencionan) en todo tipo de montes (337 ss. R.); y es posible declarar obligatoria la ejecución de planes de mejora de montes protectores (335 R.). También es posible imponer obras de mejora (y subvencionarlas) en las zonas protectoras de carácter hidrológico-forestal (341 y 343 R.) y en las que se creen por aplicación de la Ley 5/1977.

(16) Realmente, de los proyectos de ordenación económica no se dice que hayan de ser redactados por el ICONA, si bien al mismo está atribuida la administración y gestión de esos montes por el artículo $3 .^{\circ}, 2$, del Decreto-Ley 17/1971, de creación del Instituto, de modo que cualquier veleidad de independencia del titular del monte catalogado está condenada al fracaso. También pueden someterse a estos planes y proyectos los montes incluidos en la relación de protectores $\mathrm{y}$, además, los montes particulares de importancia forestal, economica y social (204 y 209 R.), pero en estos últimos la redacción por ICONA es subsidiaria de la del técnico que designe el propietario del monte y a su costa. 
la Orden de 29 de julio de 1971, los montes de utilidad pública continuarán regidos por planes facultativos anuales o periódicos de aprovechamiento y mejora, cuya duración no excederá, en principio, de cinco años, elaborados por los Ingenieros encargados del monte y aprobados por el ICONA. No se autorizará aprovechamiento que no se halle incluido en el plan, salvo determinadas excepciones (208, 212, 217 ss. y 224 R. y Normas 0. 29-7-1971).

Se incluye la caza en el plan anual de aprovechamientos, y podrá ser objeto de contratación (cumpliendo las prescripciones que dicte el ICONA) con arreglo a lo establecido en la legislación de Régimen local (221 R.).

Tras un incendio, de resultar posible a juicio del ICONA la regeneración natural, se redactará por los Servicios provinciales del ICONA un plan de cortas adecuado al caso, al cual deberá ajustarse la Entidad propietaria. En dicho plan se podrá establecer el acotamiento al pastoreo de la zona afectada por el incendio, o de parte de ella, por el tiempo que se juzgue indispensable, llegando, si fuera preciso, a su total supresión (17) (83-1 y 2 R. Inc. For.).

\section{EFECTOS RELATtVOS A LA EXPLOTACiÓN Y APROVECHAMIENTO}

Se dará atención preferente al sostenimiento del ganado de uso propio (que el Reglamento limita) de los vecinos de los pueblos y se procederá a la enajenación de los pastos sobrantes, si los hubiere, a menos que el estado forestal del monte aconseje la exclusión del ganado de granjería (18) (35 L.).

Se destinará un cuartel (porción independiente y en lo posible homogénea de un monte) al pastoreo, siempre que sea posible, siendo el aprovechamiento de los pastos del mismo objeto de un estudio técnico de acuerdo con las instrucciones vigentes (245 R.).

Continuarán los aprovechamientos en régimen especial de los

(17) Según esta norma, el ICONA debe redactar los planes de corta para «los montes que queden bajo su jurisdicción». La expresión es ambigua: desde luego, afecta a los montes estatales, de organismos estatales, así como a los consorciados; también, creemos, a los de utilidad pública, sea cual sea su propietario, porque "la administración y gestión de los montes incluidos en el Catálogo de los de Utilidad Pública» está atribuida al ICONA por el artículo 3., 2, C), del Decreto-Ley $17 / 1971$, que lo creó. El texto del artículo $84 \mathrm{R}$. Inc. For. confirma esta solución.

(18) Al pastoreo de los montes no catalogados está dedicado el artículo $242 \mathrm{R}$. De su comparación no se deduce diferencia importante en este punto entre montes catalogados y no catalogados. El aspecto que se indica en el punto siguiente sí que es realmente consecuencia de la catalogación. 
montes no comunales en tanto no se opongan a las disposiciones de la Ley y con revisión, a este fin, de las Ordenanzas (38 L.).

Es competente la Entidad propietaria para el uso y disfrute de las aguas que nazcan en los montes, mientras discurran por ellos (38-5 L.).

Previo acuerdo de la Corporación, las subastas podrán ser no de productos en pie o en el árbol, sino de productos preparados, clasificados y apilados en cargadero (267 R.).

Se constituye con el 15 por 100 del importe de todos los ingresos que tenga el monte por cualquier aprovechamiento un fondo de mejoras, que se invertirá y administrará conjuntamente para todos los montes catalogados de la misma Entidad, sin perjuicio de la contabilidad que convenga llevar para cada monte considerado como unidad independiente (19) por la Subcomisión de Montes de la Comisión Provincial de Colaboración del Estado con las Corporaciones Locales (20), que actúa a propuesta del ICONA (D. 2479/1966).

Las actividades fiscalizadoras del ICONA sobre la explotación y el aprovechamiento son importantes, como se deduce de la siguiente relación:

- La realización de cualquier disfrute o aprovechamiento exige expediente de previa licencia de disfrute por el ICONA (216 R.).

- La ejecución de los disfrutes o aprovechamientos se adaptará estrictamente a los pliegos de condiciones facultativas redactados por ICONA) y de condiciones económicas (redactados por la Entidad, ateniéndose a los precios mínimos y tasaciones determinados por ICONA) (213 y 215 R.).

- La prórroga de los plazos señalados en los pliegos de condi-

(19) Del juego del artículo 333 R. y del Decreto 2479/1966 (según el cual el fondo opera mediante un depósito en cuenta corriente en la sucursal provincial del Banco de España, cuya firma corresponde al Ingeniero Jefe del ICONA y al Jefe provincial del Servicio Nacional de Inspección y Asesoramiento de las Corporaciones Locales) resulta que sólo los dos tercios de los ingresos de cada Entidad están efectivamente vinculados a los montes catalogados de la misma, a cada uno de ellos. pudiéndose el tercio restante dedicarse a atenciones de interés forestal general de la Provincia.

(20) Antes, en la Comisión Provincial de Montes, la Diputación estaba representada por dos (un "político» y un técnico) de los diez miembros que la integraban. Ahora, convertida esta Comisión en Subcomisión de la Comisión Provincial de Colaboración del Estado con las Corporaciones Locales por el Real Decreto 2668/1977, de 15 de octubre, la representación de la Diputación se mantiene en la Orden de la Presidencia del Gobierno de 15 de enero de 1979, que regula la composición de aqué. lla y otras Subcomisiones. 
LA LEGISLACION DE MONTES EN SUS RELACIONES CON EL REGIMEN PROVINCIAL 699

ciones facultativas podrá ser concedida por las Divisiones Regionales del ICONA (214 R.).

- La autorización de cultivos o roturaciones habrá de obtenerse del Director del ICONA, que podrá denegarla o imponer las condiciones necesarias, y hacer compatibles estos aprovechamientos con las finalidades de interés general que determinen la catalogación (D. 1687/1972).

- Para la extracción de materiales (tierra, piedra, etc.) por los contratistas de Obras Públicas, se precisará la autorización del ICONA (220 R.).

- El ICONA intervendrá en las operaciones necesarias para colocar los productos forestales en cargadero (267 R.).

- Corresponderá al ICONA en relación con las subastas de productos forestales:

a) Señalar los precios índice para que la Corporación ejerza el derecho de tanteo, caso de no alcanzarse dichos precios (271 R.).

b) Autorizar a la Entidad propietaria para adjudicarse por el precio de tasación, sin sujeción al trámite de subasta, los aprovechamientos en determinados supuestos (272 y 273 R.).

- Si se ha producido un incendio, el aprovechamiento de los productos afectados por el fuego podrá ser declarado urgente por la Dirección del ICONA, la cual estará facultada para disponer su enajenación en trámite de urgencia, incluso por adjudicación directa. Cuando los productos pertenezcan a distintos propietarios, los importes de la venta se distribuirán en proporción a las tasaciones de los productos de cada uno (87 R. Inc. For.).

8. EFECTOS EN CUANTO A LA POBLACIÓN Y REPOBLACIÓN FORESTAL

De otros montes:

- Exención a los propietarios de montes particulares de extensión inferior a 10 hectáreas y que disten más de 500 metros de un monte catalogado: 
- De los deberes sobre repoblación obligatoria (325 R.).

- Y de la inclusión en concesiones administrativas (principalmente a particulares) para «realizar la siembra o plantación y consiguiente aprovechamiento maderero de terrenos aptos a tales fines» (una fórmula nueva en este campo de la Administración, aun con el antecedente del artículo 22-1 L.) (59 L. y D. 1279/1978).

De los propios montes catalogados (21):

- Para establecer consorcios (con el ICONA) destinados a repoblación será necesario que tales consorcios y su ejecución estén de acuerdo con las normas contenidas en proyectos de ordenación o plan técnico del monte de que se trate, en su caso (289 R.).

- El ICONA tiene la facultad, si se trata de montes en «zona protectora" y se han incumplido los plazos para repoblación fijados en el plan comarcal para la zona, de establecer un convenio forzoso (!) en el cual el coste de los trabajos y su ejecución correría a cargo del propio ICONA (28 L. 5/1977 y 78 D. 1279/1978).

- En caso de convenio tipo "consorcio», el ICONA sufragará, sin que se reflejen en la cuenta del convenio, no sólo los gastos de dirección técnica, los de gestión administrativa y los de guardería (lo que es normal en esos convenios), sino los que pudiera realizar «en cumplimiento de sus fines sin que para ello precisare la existencia del convenio» (52 D. 1279/ 1978).

- Pueden establecerse convenios con Entidades distintas del ICONA y con particulares para la repoblación, sometiendo los acuerdo, en su redacción, aprobación y aplicación, a las normas del Reglamento (que previenen el control por el ICONA) (296 ss. R.).

- En principio, al iniciar los trabajos de repoblación se harán efectivas las subvenciones y anticipos concedidos por el

(21) Todos los montes provinciales catalogados están sujetos al mismo régimen. En cambio, respecto a la repoblación existe entre los montes catalogados municipales una importante distinción, pues aquellos que tengan menos de 50 hectáreas y, además, sean de aprovechamiento directo por los vecinos, están exentos de los deberes de repoblación obligatoria (325 R.). 
LA LEGISLACION DE MONTES EN SUS RELACIONES CON EL REGIMEN PROVINCLAL 701

ICONA con este fin. Los anticipos están sujetos en su devolución a una escala móvil en madera (22) (306 R.).

- Se admitirán en garantía del pago de anticipos concedidos por el ICONA y de sus intereses las rentas y aprovechamientos de los montes o fincas beneficiarios en la forma y modo que en el contrato se disponga o el vuelo de la propia finca repoblada, siendo obligatorio ingresar en las arcas del ICONA el porcentaje de todos los aprovechamientos de la finca que en cada caso se pacte (310-1..$^{\circ}$.).

- En caso de declararse una zona de «repoblación obligatoria», en el Decreto en que se acuerde la repoblación se excluirá el monte catalogado (así como toda superficie que hubiere sido objeto de anterior declaración de utilidad pública) o se declarará cuál es el interés general que debe prevalecer (316-3 R.).

- Después de un incendio forestal, si la Dirección del ICONA ha juzgado posible la regeneración natural, se redacta el plan de cortas de que se trata en el apartado 6 de este capítulo; en otro caso, los trabajos de repoblación artificial habrán de atenerse estrictamente a las condiciones técnicas y plazos que determine el ICONA (23), siendo posible también la limitación del pastoreo que se indica en el citado apartado 6 (83-2 y 84-2 R. Inc. For.).

\section{Efectos en cuanto a la lucha plaguicida}

En caso de trabajos obligatorios de prevención y extinción de plagas, se satisfará el gasto con cargo al fondo de mejora de los montes catalogados de cada Entidad y a la subvención prevista en los presupuestos del ICONA para mejoras en montes públicos (24) (65-3 L. y 377-A) R.).

(22) Realmente, es la primera vez que vemos una disposición en la que el Estado, frente a sí mismo, no acepta el valor nominal de la peseta.

(23) Para los montes no catalogados se prevén explícitamente subvenciones de hasta el 50 por 100 de los trabajos pertinentes. La exclusión de los montes catalogados suponemos se debe a considerar suficiente la previsión de ayudas en los artículos 302 y 303 del Reglamento, que prevén para los montes catalogados (o cuando los solicitantes fueran las Entidades locales o "la Organización sindical») que el total de subvenciones, anticipos y ejecución material por el ICONA pueda alcanzar el 100 por 100 del presupuesto.

(24) La Ley habla, en primer lugar, de los «fondos de mejora de los montes en ordenación», los cuales silencia el Reglamento totalmente, con toda seguridad, por- 
Las cortas urgentes de prevención o saneamiento serán acordadas por la Jefatura Provincial del ICONA, se considerarán como realizaciones extraordinarias y los volúmenes extraídos serán tenidos en cuenta para su deducción en los planes siguientes (386 R.).

\section{EFECTOS EN CUANTO A POLICÍA Y RÉGIMEN SANCIONADOR}

Competencia exclusiva de la Administración forestal (el ICONA) para:

- Impedir por sí la invasión, ocupación y roturación de estos montes, sin la limitación del año y un día respecto al conocimiento o realización del acto perturbador, limitación clásica en nuestra legislación civil y administrativa (y que, en cuanto a la competencia que se señala, es efectiva respecto de los montes consorciados, protectores y otros en repoblación con pastoreo prohibido) (407 R.).

- Custodiarlos (25) (407 R.).

Aplicación de un completo capítulo del Reglamento de Montes dedicado a sancionar las infracciones en montes catalogados, distinto del que sigue dedicado a «Infracciones en montes no catalogados» (410 a 413 R.).

El primer capítulo es en bastantes casos, pero no en una parte importante de tipos de infracciones, más severo que el segundo. En el primer capítulo no hay multas de cuantía fija, sino que lo son siempre en relación con los daños y perjuicios producidos, sin

que los fondos con esta denominación no existen, pero nos tememos que no se intentó una regulación centrada en el espíritu de la Ley que se refiera a otros fondos de mejora de montes (sin la especificación de la Ley).

(25) La exclusividad en ambas competencias es difícilmente compatible con la legislación local [art. 55 del RBEL y art. 101, 2, b), de la LRL] e incluso con la Constitución (cfr. el art. 140). El artículo 55, 4, del Reglamento de Bienes intenta una sutil manera de soslayar la legislación de montes:

«En lo que concierna a los montes públicos patrimoniales se estará a lo dispuesto en la legislación especial.»

Como aquí "públicos» significa «de utilidad pública» (de otro modo existiría una contradicción in terminis), habría que entender que todos los provinciales, en virtud de lo expuesto anteriormente, están excluidos del alcance de la acción recuperadora y defensiva del ICONA. Eso implicaría dar excesiva fuerza a un inciso de un Reglamento. Creemos que la solución práctica es entender que, en caso de demora o dejadez en el ejercicio de sus deberes por el ICONA, la Diputación y los Ayuntamientos recuperan el ejercicio de las competencias que son propias de su naturaleza de entes territoriales. 
perjuicio de exigir la indemnización por los mismos, mientras que en el segundo una parte de las sanciones son de cuantía fija.

Pero realmente lo que caracteriza fundamentalmente a uno y a otro es la dependencia de unas normas sustantivas distintas, lo que provoca unos tipos «penales» distintos (26). Así, el capítulo relativo a los montes catalogados dedica 14 artículos a las infracciones en las subastas y remates y a las ejecutadas por los rematantes, artículos que no tienen equivalente en el capítulo de los montes no catalogados.

Antes de finalizar este punto debemos advertir que las normas sancionadoras de los montes catalogados deben aplicarse también (a pesar de las dificultades que derivasen de lo que acabamos de exponer) a las infracciones cometidas:

- En los montes de los cotos escolares forestales y en los terrenos ribereños repoblados por éstos, por la Organización Juvenil o las Hermandades Sindicales de Labradores (jredacción obsoleta!) (446 R.).

- En las fincas en repoblación, la cual, a juicio del Ministerio de Agricultura, revista interés forestal, si así lo hubiere concedido éste ( $285 \mathrm{R}$.).

- Y, parcialmente, en los montes y terrenos forestales incluidos en zonas declaradas protectoras de interés hidrológico-forestal (447 R.).

Las denuncias de la Guardia Civil, funcionarios del Ramo (sic) y guardias rurales se formulan por escrito ante el Alcalde del término municipal donde radique el monte, y son comunicadas por la Alcaldía y el denunciante a la Jefatura Provincial del ICONA. Los Alcaldes deben instruir unas diligencias que regula el Reglamento en el preciso término de veinte días y remitirlas a la Jefatura

(26) Según el artículo 408, 3, R., cuando la cuantía de la multa a imponer en relación con los daños causados sea superior a 100.000 pesetas, la competencia pasaría a la jurisdicción ordinaria. En este supuesto, los tipos serían realmente penales.

Sin embargo, lamentamos no considerar aceptable esta postura del Reglamento, adoptada para cubrir un aparente vacío legal. En efecto, los artículos 83 y 86 L. establecen como límite máximo de las multas que puede imponer el Ministerio de Agricultura las 100.000 pesetas, sin prever el supuesto de que, al fijar el Reglamento las sanciones en función "de la entidad e importancia de los daños causados», procediera una multa de importe superior. Pero decimos «aparente vacío» porque del texto de la Ley y del valor relativo de la peseta en el momento en que se promulgó deducimos la voluntad de no imponer sanciones superiores a las 100.000 pesetas. Las relaciones entre el Derecho administrativo de montes y el Derecho penal tienen, además, otros aspectos interesantes en los que sería impropio entrar aquí. 
Provincial del ICONA, que da vista a los interesados antes de la propuesta de resolución (27) (476 y 480 a 489 R.).

Ya que tiene un matiz de sanción, creemos interesante destacar aquí un aspecto característico de la legislación sobre montes catalogados: cuando la Entidad propietaria no ha cumplido los planes impuestos por la Administración forestal para los montes y zonas en repoblación forzosa, o los de reconstrucción de montes incendiados, o los planes comarcales de protección, se establece un convenio o consorcio forzoso. En cambio, en los mismos supuestos, pero no siendo el monte catalogado, las consecuencias pueden ser el convenio o la venta voluntaria al ICONA $y$, en último extremo, la expropiación forzosa o la ejecución subsidiaria al amparo de la Ley de Procedimiento Administrativo (320 R., 83-4 R. Inc. For. y 78 D. 1279/1978).

\section{EFectos en cuanto al Derecho fiscal}

Puede hablarse actualmente, sobre todo después de la Ley 5/ 1977, de fomento de la producción forestal, de un régimen fiscal protector de los bosques y las explotaciones forestales, pero aquí sólo nos interesan los beneficios fiscales vinculados a la inclusión de un monte en el Catálogo de los de utilidad pública. Son:

La exención absoluta de la tributación del Estado, de la que gozan los montes catalogados por el hecho de ser considerados bienes de dominio público por el solo hecho de su catalogación (28) (6 RBEL).

La exención del impuesto sobre los bienes de las personas jurídicas, de la que gozan los montes catalogados de los entes locales -si estuvieran sujetos a tributación- (29) (8 L. 5/1977).

(27) En el caso de un monte provincial habrá de considerarse a la Diputación como interesado. Desde luego, este procedimiento es uno de los puntos de la legislación estudiada que menos tiene en cuenta los intereses provinciales.

(28) Es cierto que de esa exención gozan los montes catalogados estatales, pero por el hecho de ser estatales. Análogamente, los inmuebles de dominio público de los entes públicos y territoriales gozan de exención en los tributos del Municipio y de la Provincia según las normas de Derecho local, pero sin que influya el ser o no montes catalogados. (En realidad, como el lector comprenderá, cuando el propietario y el sujeto tributario es el mismo ente habría que hablar de no sujeción.)

(29) La limitación a los montes «de los entes locales», cuando los estatales están exentos por su misma naturaleza, excluiría a los montes de los establecimientos públicos de beneficencia o benéfico-docentes, si ya no estuvieran unos y otros exentos por el artículo 49 del texto refundido del Impuesto sobre Sucesiones y normas concordantes. De modo que la limitación es inoperante y no existe privilegio. 


\section{EPILOGO}

Sobre si conviene a las Diputaciones Provinciales PEDIR LA INCLUSIÓN DE SUS MONTES EN EL CATÁlogo

Cuando, rigiendo la legislación desamortizadora, solamente se reconocía a las Corporaciones locales el derecho a la capacidad jurídica inmobiliaria sobre los montes si éstos eran incluidos en el Catálogo de Utilidad Pública, la respuesta era indudablemente positiva.

En este momento, en que cabe sintetizar los efectos estudiados en el capítulo anterior como:

a) una mayor garantía de la continuidad de la existencia, propiedad y disfrute del monte;

b) una excesiva tutela, planificación y gestión (!) por el ICONA,

la conclusión es que una Diputación de algún arraigo histórico y de buen volumen de servicios no debe pedir tal declaración, salvo en el caso de algún monte muy concreto que haya de salvar de las apetencias de algún vecino propietario o poseedor influyente.

Además, hemos de tener en cuenta que recientemente algunas Diputaciones-concretamente la de Barcelona, pero nos parece recordar que no es la única-han realizado y realizan adquisiciones de montes dentro de una política general de planeamiento del suelo. Por ello, tales adquisiciones escapan un tanto de los fines previstos en la Ley de Montes (con su preocupación por el disfrute económico y la explotación) e inciden de lleno dentro de la creación y gestión del "patrimonio del suelo», al que el apartado 1 de la Base 45 de la Ley 41/1975, de 19 de noviembre, de Bases del Estatuto de Régimen local, dedica el siguiente párrafo:

«Las Diputaciones provinciales podrán constituir su patrimonio del suelo, colaborando con las funciones que en este orden corresponden a los Municipios.»

Pero, a pesar de ello, tal patrimonio-o la parte montañosa de él-está sujeto al peligro de ser incluido dentro del Catálogo de 
marras, por lo menos mientras no se articule la Base (30). En efecto, presentando un ejemplo concreto, la Diputación de Barcelona, cuando ha efectuado adquisiciones de terreno forestal, lo ha hecho dentro de las áreas de los parques naturales provinciales, declarados así por el Plan General de Ordenación de la Provincia, aprobado en 1963; ahora bien, en el momento en que a esa declaración se sobreponga la de parque natural por Decreto del Ministerio de Agricultura, éste podrá a su vez declarar los bosques provinciales incluidos en el Catálogo de Montes de Utilidad Pública.

Los caminos para garantizar la continuidad, existencia, propiedad y disfrute del monte provincial sin los inconvenientes de la declaración de parque natural pueden ser:

a) Declarar el monte provincial adscrito a un servicio público, o bien abierto al uso público.

b) Quedar incluido el monte provincial en una "reserva de suelo», "paisaje protegido», «sistema general de protección», "área rural mínima», etc., de un Plan General o Especial de Ordenación, Director Territorial de Coordinación, de unas Normas Complementarias o Subsidiarias de Planeamiento. Aquí me permitiré dos consejos sotto voce:

- evitar, en lo posible, el empleo de la expresión «parque natural» o análoga, para no facilitar al Ministerio de Agricultura el inicio del proceso que termina con la catalogación del monte;

- delimitar el territorio o área de que se trata de modo que exista gran número de propietarios privados, porque, como ya hemos insinuado anteriormente, los técnicos del Ministerio de Agricultura e ICONA han dado generalmente muestras de un excesivo respeto a la propiedad privada, quizá porque los intereses políticos mediatizaban la actitud de sus órganos rectores.

Hay un tercer camino para conseguir el efecto a) del número 1 de este epílogo y evitar el b). Es el que siguió Navarra ya en tiempos del Generalísimo Franco: conseguir del Gobierno que se delegara en su Diputación "el ejercicio de las funciones que correspondan o puedan corresponder al ICONA».

(30) Por razones no técnicas, la Base citada, como muchas otras, no será jamás articulada (ya ha sido derogada por la Ley 47/1978, de 7 de octubre), pero estamos seguros de que, con alguna variante, se recogerá en la próxima legislación sobre Régimen local. 
LA LEGISLACION DE MONTES EN SUS RELACIONES CON EL REGIMEN PROVINCLAL 707

La delegación se confirió mediante Decreto 3640/1974, de 20 de diciembre, publicado en el Boletin Oficial del Estado de 23 de enero de 1975, en la sección III, «Otras disposiciones», y que, por ello, pasó bastante inadvertido, razón por la cual lo transcribimos como anexo.

Se nos podría decir que el ejemplo no es válido porque la Diputación de Navarra es una de las forales. Incluso esa tesis se podría apoyar en el principio del artículo $1 .^{\circ}$ del citado Decreto:

«La Diputación Foral de Navarra ejercerá en el ámbito de su territorio las facultades que por derecho propio son de su competencia y por delegación...»

Algo hay de esto, pero creemos que más bien existe una voluntad y una tradición, como se desprende de la lectura, en el Diccionario de Legislación Aranzadi, del artículo Montes - Derecho Foral - Navarra (págs. 13648 y ss. del tomo XI, 1.a edición).

En realidad, no hay nada en el Decreto 3640/1974 que se oponga al régimen local común. Por tanto, las Diputaciones provinciales no sujetas a un ente preautonómico o autonómico pueden obtener análogas competencias por delegación que la Diputación de Navarra. Y me atrevería a decir que los entes autonómicos pueden y deben obtener dichas competencias, porque la Administración forestal, en líneas generales, es de las que parece más adecuada para tales entes.

\section{ANEXO}

Decreto 3640/1974, de 20 de diciembre, por el que se delegan en la Diputación Foral de Navarra funciones del Instituto Nacional para la Conservación de la Naturaleza (ICONA)

La Diputación Foral de Navarra, en uso de las facultades que tiene atribuidas en virtud de la Ley de 16 de agosto de 1841 y disposiciones posteriores, viene ejerciendo una intensa y eficaz labor de promoción de la riqueza forestal navarra.

Por este motivo, y con el fin de lograr una unidad de acción que permita desarrollar una política integral de conservación de la naturaleza en Navarra, se considera conveniente delegar en la Diputación Foral las facultades que, con arreglo a la legislación vigente, corresponden al Instituto Nacional para la Conservación de la $\mathrm{Na}$ - 
turaleza, en aras de una mayor eficacia administrativa, al concentrar en un solo Organismo el planeamiento y ejecución de todas las acciones de la Administración Pública tendentes a la conservación de la naturaleza. Todo ello sin perjuicio de la alta inspección del Estado, que garantice el cumplimiento de los objetivos en que se inspira la política nacional en la materia, que será ejercida por el Ministerio de Agricultura, a través del Instituto Nacional para la Conservación de la Naturaleza. Con tal fin se han realizado los estudios pertinentes por los Departamentos ministeriales interesados y por la Diputación Foral de Navarra y, ultimados los mismos, se ha elaborado el correspondiente anteproyecto con audiencia y conformidad de la citada Corporación.

En su virtud, a propuesta de los Ministros de la Gobernación y Agricultura y previa deliberación del Consejo de Ministros en su reunión del día 22 de noviembre de 1974,

\section{I S P O G O :}

Artículo 1. La Diputación Foral de Navarra ejercerá, en el ámbito de su territorio, las facultades que por derecho propio son de su competencia y, por delegación, las funciones que corresponden o puedan corresponder al Instituto Nacional para la Conservación de la Naturaleza (ICONA), según la legislación vigente.

La Diputación Foral deberá llevar a cabo en Navarra las actividades propias del Instituto en el grado y proporción necesaria para conseguir el nivel óptimo posible en la conservación de la naturaleza.

En todo caso queda siempre a salvo la Alta Inspección del Estado conducente al cumplimiento de sus fines propios y a los señalados en esta disposición.

Art. 2. La Alta Inspección que corresponde al Estado se ejercerá por el Ministerio de Agricultura, a través de ICONA.

Art. 3. La Diputación Foral, en el mes de octubre de cada año, elevará al Ministerio de Agricultura los planes de actuación en materia de conservación de la naturaleza aprobados en aquella Corporación para el año siguiente, para conocimiento en lo que se refiere a las facultades propias sobre esta materia, conformidad en cuanto a facultades delegadas y aprobación para proyectos, trabajos u obras, total o parcialmente financiados con fondos del Estado. 
Art. 4..$^{\circ}$ En el ejercicio de la Alta Inspección corresponderá de modo específico al ICONA la realización de las siguientes funciones:

a) En relación con los planes de actuación anteriormente indicados, comprobar si se ajustan a los objetivos generales de la política nacional en materia de las competencias del Instituto, así como a lo dispuesto en el presente Decreto.

b) Aprobar técnicamente los proyectos y programas en cuya financiación participe el Estado.

c) Inspeccionar técnica y administrativamente las obras y servicios ejecutados por la Dirección de Montes de la Diputación Foral en el supuesto considerado en el apartado precedente, aprobando las cuentas correspondientes.

d) Recabar de la Dirección de Montes de la Diputación Foral cuantos informes, datos y documentos estime necesarios para conocimiento del desarrollo de los planes de actuación y evaluación de sus resultados.

Art. 5. La Diputación Foral deberá mantener los Servicios de Conservación de la Naturaleza necesarios para el cumplimiento de los compromisos derivados de la presente disposición. El personal facultativo, administrativo y de guardería será designado por la Corporación Foral, conforme a sus propias normas.

La fijación de la plantilla mínima que deban tener los Servicios de la Diputación se hará de común acuerdo con la Dirección General del ICONA.

Art. 6. $\mathrm{El}$ personal administrativo y de guardería actualmente al servicio del ICONA tendrá derecho a adquirir inmediatamente la condición de funcionario de nómina y plantilla de la Diputación Foral, con el encuadramiento que le corresponda y quedando previamente en la situación administrativa que le sea de aplicación. A todos los efectos reglamentarios se les reconocerá la antigüedad que tuvieren en sus respectivos cargos actuales.

Art. 7. La gestión técnica y administrativa de los montes del Estado, que actualmente realiza la Diputación Foral, continuará rigiéndose por lo dispuesto en el Real Decreto de 30 de junio de 1930 y acuerdos posteriores concordantes.

La gestión técnica y administrativa de los demás montes del Estado situados en Navarra se realizará también por la Diputación Foral, con arreglo a las mismas normas establecidas en las disposiciones expresadas en el párrafo anterior. 
Las facultades delegadas a la Diputación Foral, en relación con estos montes, se limitan a la administración y gestión técnica de los mismos, sin que, por lo tanto, pueda constituir gravámenes sobre dichos montes, modificar los existentes o ejercer cualquier otra facultad que no haya sido objeto de delegación expresa.

Art. 8. La Diputación Foral queda subrogada en los derechos y obligaciones del ICONA en Navarra contraídos hasta el momento, respetando íntegramente las situaciones jurídicas nacidas en virtud de las actuaciones de dicho Organismo.

Art. 9.' La Diputación Foral transferirá antes del fin de cada año natural al ICONA el 90 por 100 íntegro del importe de los aprovechamientos enajenados de los montes propiedad del Estado y el total del importe de las indemnizaciones por daños de los expedientes de sanciones, quedando el 10 por 100 restante, así como el importe de las multas por sanciones, a disposición de la Diputación como compensación por los gastos que realice.

Art. 10. De conformidad con el «Texto en el que se fija la aportación de Navarra al sostenimiento de las cargas generales de la Nación y se armoniza su peculiar régimen fiscal con el general del Estado», publicado por Decreto-Ley 16/1969, de 24 de julio, la Diputación Foral recaudará en su territorio las tasas y exacciones parafiscales que la legislación vigente otorga al ICONA, cuyo rendimiento se invertirá en la financiación de los planes de conservación de la naturaleza de dicha Corporación.

Art. 11. Las discrepancias que se susciten entre el Ministerio de Agricultura y la Diputación Foral en aplicación de lo dispuesto en el presente Decreto serán resueltas por una Comisión mixta, compuesta por dos representantes de cada una de las partes, actuando como Presidente el Magistrado del Tribunal Supremo que lo sea de la Junta Arbitral a que se refiere el Decreto-Ley 16/1969, de 24 de julio. El incumplimiento por la Diputación Foral de las Resoluciones de la Comisión mixta a que se refiere esta estipulación será causa para la anulación por la Administración del Estado, en todo o en parte, de la delegación conferida.

Art. 12. El presente Decreto entrará en vigor el mismo día de su publicación en el Boletín Oficial del Estado.

Así lo dispongo por el presente Decreto, dado en Madrid a 20 de diciembre de 1974.-Francisco Franco.-El Ministro de la Presidencia del Gobierno, Antonio Carro Martínez. 
REVL-1980, núm. 208. TARRATS Y FONTANELLES, EDUARDO. LA LEGISLACION ESPAÑOLA DE ...

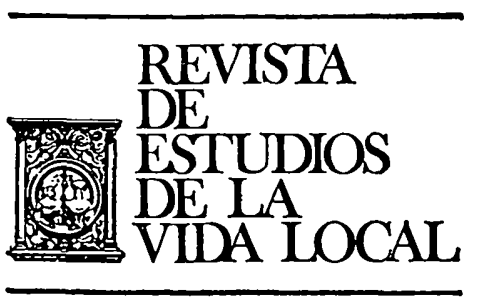

II. CRONICAS

REVL-1980, núm. 208. TARRATS Y FONTANELLES, EDUARDO. LA LEGISLACION ESPAÑOLA DE ... 
REVL-1980, núm. 208. TARRATS Y FONTANELLES, EDUARDO. LA LEGISLACION ESPAÑOLA DE ... REVL-1980, núm. 208. TARRATS Y FONTANELLES, EDUARDO. LA LEGISLACION ESPAÑOLA DE ... 